\title{
El demonio \\ neón (2016): \\ una estética de \\ la falsedad
}

\author{
Miguel Sánchez Soto \\ sansomiguel@gmail.com
}

Universidad de Guadalajara, México

FECHA DE RECEPCIÓN abril 3, 2019

FECHA DE APROBACIÓN junio 10, 2019

https://doi.org/10.32870/ elojoquepiensa.v0i19.324
RESUMEN / El presente trabajo propone una reconstrucción de la poética estética del filme $\boldsymbol{E l}$ demonio neón (2016), empleando un análisis hermenéutico de las relaciones que se establecen entre, las referencias hipotextuales a las tradiciones judeocristianas y el mito de Narciso articuladas en el discurso audiovisual y la exposición dialéctica de la consecución de lo bello a través de diversos medios como deber y fin último del ser humano.

Palabras Glave / intertextualidad, hipotextualidad, falsedad, estética.
ABstract / The present work proposes a reconstruction of the aesthetic poetics of the film The Neon Demon (2016), using a hermeneutical analysis of the relationships established between, the hypotextual references to the Judeo-Christian traditions and the Narcissus myth articulated in the audiovisual discourse and the dialectic exposure of the achievement of the beautiful, through different ways, as a duty and ultimate goal of the human being.

KEYWORDS / intertextuality, hipotextuality, fake, aesthetics. 
en determinado género). Los dos textos más evidentes que funcionan como atractores de sentido ${ }^{1}$ son, por una parte, el relato bíblico de la caída de Lucifer, ángel de luz, a causa de su soberbia, y por otra, el mito de Narciso. Sendos textos se encuentran vinculados por dos constantes interesantes para la lectura que este documento pretende realizar: 1) la cuestión corpórea, con la impronta de la hybris ${ }^{2}$ y 2) la temática de lo falso encarnado en sus diversas formas: el engaño, la mentira, el timo.

Tomaré como unidad de análisis la secuencia, entendiendo que esta se articula en la relación de sentido que se establece entre los diálogos (aseveraciones y puntos de vista argumentativos) y los planos del filme. Dichas secuencias fueron seleccionadas por tener un vínculo con los hipotextos que iteran la tesis estética de la obra. Por esta razón pondré énfasis indistintamente en el dialogismo que presentan los personajes y en las diversas dimensiones y lecturas que puede ofrecer el plano.

\section{LA NARRATIVA Y LO FALSO}

Si pensamos el filme como una propuesta de lectura correlacionada y regulada por las distintas iteraciones que buscan construir un marco global de sentido, podremos leer la primera secuencia o íncipit de la película como un epígrafe que condensa, en sí mismo, su postura permitiendo visionar el filme que aquí se trata como un ensayo audiovisual sobre lo falso.

En dicha secuencia, la ficción audiovisual nos presenta, en un movimiento de cámara en zoom out, la imagen de la cabeza de Jesse inmóvil con los ojos abiertos diluidos en el horizonte, para develarnos - segundos después - el motivo aparente de esa inmovilidad: un cuello con un tajo mortal; un cuerpo exangüe. Esa aparente quietud es interrumpida por

${ }^{1}$ Piénsese visualmente en este concepto a partir de los atractores de Lorenz (1993).

${ }^{2}$ La hybris entendida como exceso o desmesura que produce un castigo por parte de los dioses. la luz de un flash, y a contraplano la mirada incisiva - quizá excitada - de Dean, un fotógrafo amateur.

Lo que parece ser la escena de un crimen expuesta con suma delicadeza y, hasta cierto punto, cuidada con armonía de color y composición, con una iluminación con base en luces neón e interrumpidas por el flash estroboscópico de la cámara del fotógrafo, no es otra cosa que una escena falsa. La ruptura de esta escena es producida por contraste, cuando en la siguiente secuencia aparece Jesse frente al espejo limpiándose la sangre de utilería y el maquillaje con bastante trabajo. Desde esta construcción diegética el filme nos alerta sobre la centralidad del tópico de lo falso, donde dicha falsedad está engastada en la tensión dialéctica entre el ojo ávido y deseoso de belleza y el cuerpo que lo encarna.

Por otra parte, existe una constante alusión a la mentira como hábito que le permite a Jesse sobrevivir. Jesse tiene que mentir, primero, para poder cercenar las agudas preguntas sobre su pasado y su familia; asegura que murieron y con ello gana entre sus nuevas "amigas" una actitud de condescendencia. Miente, luego, para poder obtener un trabajo, pues es menor de edad, y ante la actitud omisa y solapadora de la agencia de modelos que la desea contratar pasan por alto la falsificación de la firma de sus padres y sugieren cómo mentir en el tema de la edad con mayor precisión. Miente a Dean, el chico que la pretende, y quien en la primera escena vemos tomándole las "inquietantes" fotos donde yace muerta, cuando éste le pregunta sobre lo que verdaderamente piensa la agencia de modelos empleadora de Jesse ha dicho sobre su trabajo, , las fotografías de los primeros planos y le dice que no dijeron nada, cuando en realidad fueron negativos los comentarios sobre estas.

El centro argumental en el que se desarrolla la acción narrativa estriba en la caída, transformación o decadencia, de Jesse: de un estadio primario en el que impera la inocencia, corporeizada en la hermosura natural, a un estado de soberbia inducido por el mismo conocimiento y poder que 
trae aparejado - en la sociedad occidentalizada - poseer un cuerpo bello.

En el aspecto narrativo también será posible observar que la relación entre los personajes femeninos está puesta en clave de falsedad. La traición es un elemento constante, donde las oportunidades de sobresalir, en ese restringido mundo, son exiguas y en donde la canibalización - metafórica- entre las rivales es representada como producto natural de la interacción entre los diferentes cuerpos hermosos.

A continuación, abundaré en los niveles que he señalado como nodos de esta correlación entre cuerpo, intertextos y el tópico de la falsedad como una configuración de lo bello.

\section{LA RELACIÓN ENTRE LO FALSO Y LA INTERTEXTUALIDAD}

En El demonio neón la red de significados que dirigen a otros textos tiene como núcleo de sentido la iteración de lo falso y su relación con una estética determinada. Esta relación descansa en la figura del demonio, antes que adversario del hombre como en la tradición judeo-cristiana, como una representación distorsionada, falsa, de lo divino. En este texto utilizaré — para verter más precisión sobre mi argumento principal- el concepto de hipertextualidad tomado de Genette (1989 [1962]). Si bien es cierto que el debate sobre la intertextualidad ha tomado nuevos derroteros (Worton y Still, 2001) y se ha actualizado desde la concepción de Genette, y puede objetarse mi elección aduciendo la lejanía temporal e intelectual dentro del campo de estudio de la ficción, debo aclarar que estos aportes no ponen en entredicho el centro conceptual del trabajo de Genette, ni las contribuciones más recientes ganan en sistematicidad y claridad a la concepción y entendimiento de los textos prístinos de Kristeva y Barthes sobre el fenómeno.

En este sentido, la claridad que tiene la obra genettiana para explicar qué es un hipertexto es potentísima. Genette (1989) expone que hipertexto es un concepto para definir la relación entre un texto base o fuente (también llamado hipotexto, o texto A) y otro derivado (texto B), del que no habría forma de tener una significación compleja sin la existencia de ese texto troncal.

Si bien durante la década de los 90 el auge y saturación de producciones académicas que tenían por centro el concepto, su aplicación y uso en el campo de lo literario produjo que diversos investigadores señalaran el uso desmesurado y trivial del concepto, el empleo que hago de éste no pretende provocar nuevos derroteros en la dimensión teórica, empero su versatilidad como marco explicativo es necesaria para entender la relación entre la estética propuesta por el filme y los hipotextos que revisaré más adelante.

Bajo estos términos es posible aseverar que la relación intertextual más superficial que exhibe el filme de El demonio neón es la que lo liga con ciertas referencias a la representación del demonio existente en el compendio de relatos bíblicos, más en el orden de veterotestamentaria, como se conoce en la tradición cristiana, o Tanakh, como lo nombra la tradición judía.

El filme iterará a través de las referencias, reconstruidas y reapropiadas desde el discurso visual, los atributos del demonio como ser opositor a la divinidad que yacen en dichos libros. Aquí rescato como ejemplo tres secuencias en el filme que se encuentran enlazados a estos hipotextos: 1) la referencia a Lucifer como un ser de luz, 2) la fundición y adoración de un becerro de oro (falso dios) por parte del pueblo judío en el éxodo y 3) la caída de Lucifer por su soberbia (Is 14:12-14) y deseo de ser "semejante" a la deidad.

\section{IN NUMERABLES PIEDRAS PRECIOSAS ADORNABAN TU MANTO}

Una de las primeras relaciones tendidas en torno a este hipotexto se encuentra de forma extratexual en los carteles que sirvieron para promocionar la película. En uno de estos 



\section{(...) E HIZO DE ELLO UN BECERRO DE FUNDICIÓN}

En este sentido y bajo esta lectura, en la secuencia donde Jesse es fotografiada seremos testigos de la forma en que la relación entre los cuerpos que habitan el espacio y su forma de ser visualizados que propone la película cambian a partir de este punto de inflexión narrativa e hipertexual (en su relación-reconstrucción de los hipotextos bíblicos que aluden a la figura demoniaca).

En el inicio de la escena, Jesse es despojada de su ropa hasta quedar desnuda, se apaga la iluminación de luz blanca y fría, y en la penumbra aparece la luz cálida, que servirá como catalizador, reforzador del color dorado con que el fotógrafo ilumina-pinta el cuerpo desnudo de Jesse.

La iluminación y la disposición cromática presentan una gradación. En esta escena se aprecia uno de los puntos de inflexión en torno a la configuración tímica del personaje principal. En tanto que las primeras secuencias habían estado orientadas hacia la composición de planos empleando una gama de colores fuertes, iluminación nuevamente por luces neón y estroboscópicas, siendo contrastada o alternada por secuencias con planos orientados a los colores pastel, opacos. Esta secuencia de la "unción áurea" de Jesse está ambientada por planos donde predomina el color blanco, como fondo y como color del ropaje interior de Jesse; el negro, que porta el fotógrafo; y el dorado: tinte que el fotógrafo emplea en las luces cálidas, y también con el que "baña" el cuerpo de Jesse para la sesión fotográfica. A partir del baño dorado al cuerpo de Jesse, se realiza un corte de escena, en donde se elide la visión del espectador, reservando celosamente para cualquier ojo, como un acto iniciático, lo ocurrido.

Considero esta "unción áurea" una inflexión en la iluminación y la orientación cromática de los planos de manera que incide en la interpretación de este acto como iniciático, ya en el nivel metafórico como una iniciación a la vida sexual, ya en el narrativo como una iniciación en el mundo del modelaje, y que a su vez proponen una lectura desde otro hipotexto. Así, las incrustaciones doradas que el maquillaje de Ruby proporciona al rostro de Jesse se relacionan en este ecosistema de signos y sentido, con una nueva construcción de significado a partir del hipotexto de la idolatría del pueblo hebreo o "adoración del becerro de oro". El pueblo emancipado de Israel en el desierto, ante la ausencia de Moisés, construye un becerro áureo y le adoran. Esta actividad es motivo para que su deidad se moleste y piense en destruirlos, debido al cambio de dios y su representación material tan penada por dicha religión.

La composición de esta relación hipertextual estriba entonces en dos núcleos grandes de significación que a través de sus relaciones o imbricaciones estructuran el relato. Uno está constituido por elementos alusivos al cuerpo, a una sexualización de ese cuerpo. Las denotaciones a un despertar sexual son, de alguna forma, más que evidentes. La soledad de los cuerpos, el vacío inmaculado del blanco que sirve de background; la asimetría visible entre la posición experimentada del fotógrafo e inexperimentada de Jesse como modelo; el "baño" de pintura dorada, o la unción con color dorado; la interpelación de Jesse a través de órdenes por parte del fotógrafo en el comienzo de la sesión.

El otro está constituido por los elementos de sentido que existen en el hipotexto del becerro dorado: primero una alegoría al pasaje donde los israelitas destinan los sarcillos de oro de sus hijos y esposas a la fundición para elaborar un becerro al cual adorar. Este núcleo significativo es traspuesto de forma que el tinte dorado que vierten sobre Jesse, así como el maquillaje pan de oro del rostro, nos remite de manera sutil a los versículos del Éxodo.

${ }^{2}$ Y Aarón les dijo: Apartad los zarcillos de oro que están en las
orejas de vuestras mujeres, de vuestros hijos y de vuestras hijas,
y traédmelos. ${ }^{3}$ Entonces todo el pueblo apartó los zarcillos de
oro que tenían en sus orejas, y los trajeron a Aarón; ${ }^{4}$ y él los
tomó de las manos de ellos, y le dio forma con buril, e hizo de
ello un becerro de fundición. Entonces dijeron: Israel, estos son 
tus dioses, que te sacaron de la tierra de Egipto. ${ }^{5} \mathrm{Y}$ viendo esto Aarón, edificó un altar delante del becerro; y pregonó Aarón, y dijo: Mañana será fiesta para Jehová. ${ }^{6} \mathrm{Y}$ al día siguiente madrugaron, y ofrecieron holocaustos, y presentaron ofrendas de paz; y se sentó el pueblo a comer y a beber, y se levantó a regocijarse. ${ }^{7}$ Entonces Jehová dijo a Moisés: Anda, desciende, porque tu pueblo que sacaste de la tierra de Egipto se ha corrompido (Ex, 32:2-7).

La metáfora basada en el tópico de la falsedad emplea los elementos de una suplantación del dios inmaterial por uno material, en donde el cuerpo de la modelo es una metáfora de dicha sustitución llevada a cabo de la siguiente manera. Existe a través de este referente textual un sistema de sustituciones, donde lo material está ligado con lo falso, y lo verdadero con lo inmaterial: Jesse es representada dentro de este sistema de referencias sobre la belleza y erigida como el becerro de oro que todos adorarán y que por transferencia de sentido entre los hipotextos representa lo falso y caduco, lo propenso al castigo por parte de la divinidad. En sendos casos, el becerro de oro y Lucifer encarnan una entidad contraria a la divinidad que produce orden (lo divino tendría los atributos de inmaterial y perenne y por tanto verdadero). Dichas entidades son propiciadoras de "escándalo" (Girard, 1999), de algo diabólico [FIGURA 2].

\section{iCómo caíste del cielo, OH LUCERO, HIJO DE LA MAÑANA!}

En lo que respecta al hipotexto de la "caída" de Lucifer, en el filme no se presenta una reelaboración demasiado complicada. Puede advertirse que está dispuesto de una forma directa: literalmente Jesse cae (o es arrojada) a una piscina vacía. En la diégesis Jesse aparece con un vestido color verde menta, balanceándose en el borde de trampolín de una piscina sin agua, mientras que al fondo aparecen los rascacielos

\section{FIGURA 2.}

\section{El demonio neón}

(Nicolas Winding Refn, 2016). 
de la ciudad de Los Ángeles. Acto seguido, aparece Ruby, y Jesse le ofrece un discurso sobre el conocimiento que tiene de su belleza natural como una "cosa" que las demás mujeres persiguen. De este conocimiento sobre su belleza, como forma de tomar conciencia sobre la peligrosidad intrínseca a una belleza "natural", la narrativa que obra en esta ficción audiovisual propone que se gesta la soberbia, como tipo de maldad, en Jesse. Este conocimiento distorsionado que tiene Jesse sobre su propia belleza es lo que la hace "peligrosa", citando las palabras de su madre, quien la concibe, según el recuerdo de Jesse como una mujer peligrosa, pues tiene lo que otras mujeres no pueden, ni artificialmente (inyectándose, o bien quitándose partes) ni con disciplina (ejercicio, o matándose de hambre).

Esta escena también es plausible de leerse extendiendo su significado a una reelaboración del hipotexto griego, donde Narciso es aniquilado por el embelesamiento y el deseo de besar su propio reflejo en la superficie acuosa. En la interpretación del mito, Narciso es víctima de la visión distorsionada por egotismo entumecedor (o narcótico: del griego narkoyn, entumecer) de los sentidos a través de lo falso, ya que el reflejo sería también una forma de artificio. Este egotismo narcótico de Jesse tiene una transformación a lo largo del filme: de ser consciente de su belleza y tener una actitud inocente, hasta tomar consciencia de ser deseada por los demás y jactarse orgullosamente de su "poder" radicado en la hermosura superficial y corpórea ${ }^{3}$. Jesse al proferir este discurso sobre la peligrosidad que conlleva la hermosura en el trampolín de una piscina vacía, permite llevar a una reconstrucción que complejiza este mito. Jesse encuentra su reflejo en el deseo que tienen sus competidoras y amigas por la juventud y hermosura que posee, y es ante ese reflejo que es obnubilada. La caída al estanque vacío, o al pozo del castigo por el pecado del orgullo es superpuesto desde una lógica moralizante y

\footnotetext{
${ }^{3}$ Aunque esta hermosura aparentemente superficial es expresada como algo inmaterial vinculado a la carne que puede transmigrar a (o poseer y ser poseído por) otros cuerpos a través de la ingestión.
}

cristiana, desde tiempos inmemoriales, al ahogamiento del mismo Narciso [FIGURA 3].

La aparición iterada de los espejos, desde la cámara fotográfica como una especie de espejo mecánica y fijadora, pasando por la ruptura de espejos y triangulaciones especulares, hasta el ojo que es vomitado y engullido en la secuencia final, es una reinterpretación del mito griego, a la luz de los textos judecristianos que profundizan sobre la soberbia como vicio o pecado del ser humano.

De esta forma el discurso que pronuncia Jesse estando en el trampolín de la piscina vacía es el culmen de su conocimiento falso sobre su hermosura, y una exposición del grado de soberbia que dicho conocimiento le ha conferido o provocado, y también funge como correlato del diálogo que tiene con Dean en un par de secuencias anteriores. En este Dean le increpa el cambio de una Jesse inocente a una Jesse visiblemente altanera y orgullosa de su belleza, puesto que, para él, Jesse no debería querer ser como las otras modelos, y lo que representan (falsedad, traición, decadencia, artificialidad). Ante esta manera de pensar, Jesse le retruca a Dean que "ella no quiere ser como las otras modelos", más aún, "ellas quieren ser como yo".

En la literatura veterotestamentaria no se aborda con mayor claridad la caída de Lucifer, pero queda explícito que fue a causa de que soberbiamente quiso ser como dios. En la propuesta de El demonio neón, Jesse va más allá, en la sustitución de elementos puede leerse que, las otras modelos son las verdaderas demoníacas, que a través de la falsedad y artificio de las modificaciones corporales quieren obtener aquello que no obtuvieron por natura, y que en su aspiración a ser como ella está la verdadera blasfemia, porque Jesse es, en su ilusión, dios.

\section{LA CORPOREIZACIÓN DE LO FALSO}

En uno de sus textos Yehya (2001), al hablar cómo las modelos participan de su cuerpo como escaparate para el 
mundo de la moda, las presentaba como producto y efecto del romanticismo de la siguiente manera:

La erradicación de la muerte, o por lo menos la prolongación de la vida, ha sido una de las metas que han definido el progreso científico; la modelo, al igual que el monstruo de Frankenstein, son también triunfos tecnológicos y, como escribe Theodore Roszak, 'el monstruo de Frankenstein es monstruoso no simplemente por ser feo, sino porque es un cadáver viviente. El triunfo final en la extensión de la vida es un collage de partes corporales muertas, cosidas juntas y forzadas a regresar a la vida' (Yehya, 2001, pp. 168-169).

En el filme que ahora nos convoca, Refn va más allá y en su conjunto, propone que no solo es la extensión de la vida a través de ese collage de partes muertas, sino la misma extensión de la belleza, otorgándoles de ese modo una misma condición a lo artificial, a lo falso, y a lo caduco con lo muerto.

Repetidas veces es mencionada esta rivalidad entre belleza artificial y belleza natural o cruda en el filme, evidenciando argumentos retóricos y visuales en los que "gana" siempre esta última.

Ejemplos de esto los encontramos en dos momentos esenciales y correlacionados: primero, en la plática de chicas que tienen Gigi, Sarah, Ruby y Jesse ante el espejo de los sanitarios, y segundo, cuando el diseñador y Dean conversan. En este primer diálogo Ruby presenta a las modelos a Jesse como su nueva amiga, y tienen el siguiente intercambio:

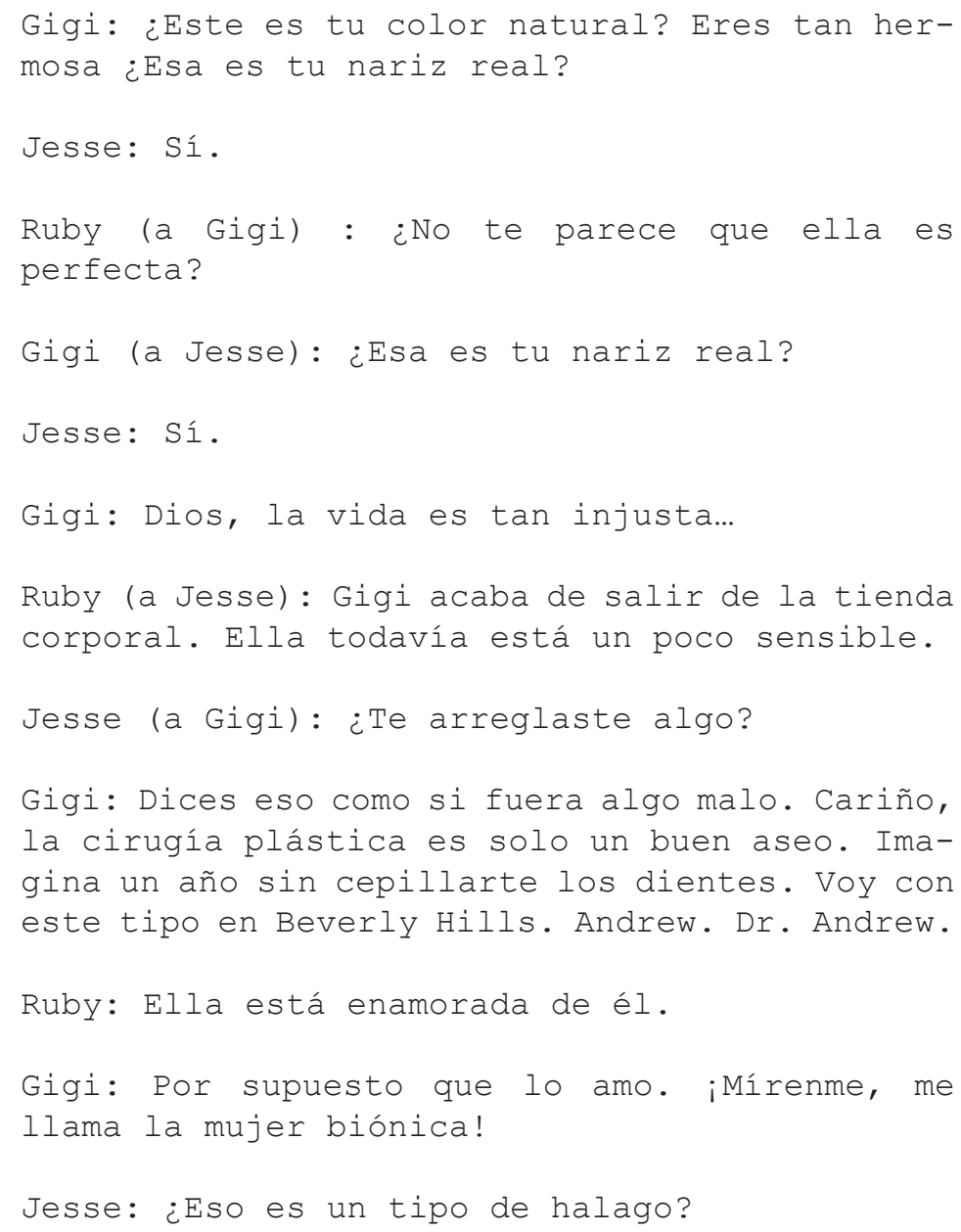


En este intercambio dialógico también queda expuesta la consideración de dos tipos de paradigmas calológicos, o sobre lo bello: uno que es expuesto por Gigi que asume que la belleza tiene que ser algo que se adquiere a través de un hacer-transformar y que tiene un sentido de recompensa o cambio; por eso, para ella la belleza que ostenta Jesse es "injusta" pues no realizó ningún tipo de esfuerzo, no le ha "costado" nada. Y en cambio, la postura sobre la belleza de Jesse es que ha tenido la fortuna de ser bella y ser bella en esta sociedad es una fuente de riqueza.

En dicha expresión de la inocencia por parte de Jesse se transluce toda una postura estética y desde luego ética: aquellos cuerpos que son modificados artificialmente pueden lucir, ser semejantes a lo bello que procede ex natura, y con ello a lo divino, sin embargo, este deseo de equipararse con lo divino es tomado como una postura demoniaca. Estas bellezas artificiales tienen que a través de infringir violencia sobre el cuerpo bello que es deseado e ideal para resarcir un orden que ha sido trastocado por su llegada. Además de infringir esa violencia sobre ese "chivo expiatorio" (Girard, 1986) es necesario asimilarlo, pero asimilarlo engulléndolo, ingiriéndolo.

Lo que nos conduce a un falso dilema estético que se propone también en la escena de la charla en el baño de mujeres, y en el encuentro y presentación de Jesse con las amigas del mundo del modelaje. Mientras que la composición fotográfica juega con la triangulación de elementos en los planos y la superposiciones de imágenes en los espejos, la conversación se gesta sobre la suposición de que llos mercadólogos y diseñadores de lápices labiales los nombran usando una temática sexual o comestible, porque -aseguran ellas-, las mujeres son más propensas a comprar esos adminículos identificándose con esas dos opciones. Así enumeran diversos ejemplos: Red Rum $^{4}$, Black Honey, Plum Passion... Pink Pussy. Con este pequeño juego de palabras también se establece una directriz sobre la temática caníbal de película, pero basándola en

${ }^{4}$ Quizá un guiño al anagrama de "Murder" (asesinato), hecho famoso en El resplandor (The Shining, Stanley Kubrick, 1980). una declaración sobre lo bello, es decir, de carácter estético. Aseguro que este falso dilema sobre ser comida o sexo es, precisamente, falso, porque en la proposición que se hace sobre la belleza natural es la siguiente, un ser dotado de suma belleza es un ser humano sobre el que imperan las reglas de lo sexual. Es decir, es humana porque se puede tener sexo con ella, si no se puede tener sexo con ella, no es humano y por lo tanto es comestible. Siendo que comer es algo natural para el ser humano, la ingesta de las propiedades de los objetos es algo también natural y además necesario para la humanidad.

En tanto que, se encontrará como correlato de esta primera proposición sobre la estética de lo falso o lo artificial, la escena en la que Jesse y Dean coinciden en un restaurante con el diseñador, Gigi y otra modelo. El diseñador sostiene que la supremacía de la belleza natural sobre la artificial además avanza hacia un argumento donde prima la belleza experimentada por el sentido de la vista antes que la belleza interior o subjetiva. Para demostrar su argumento le pide a Dean que compare primero entre Gigi y Jesse:

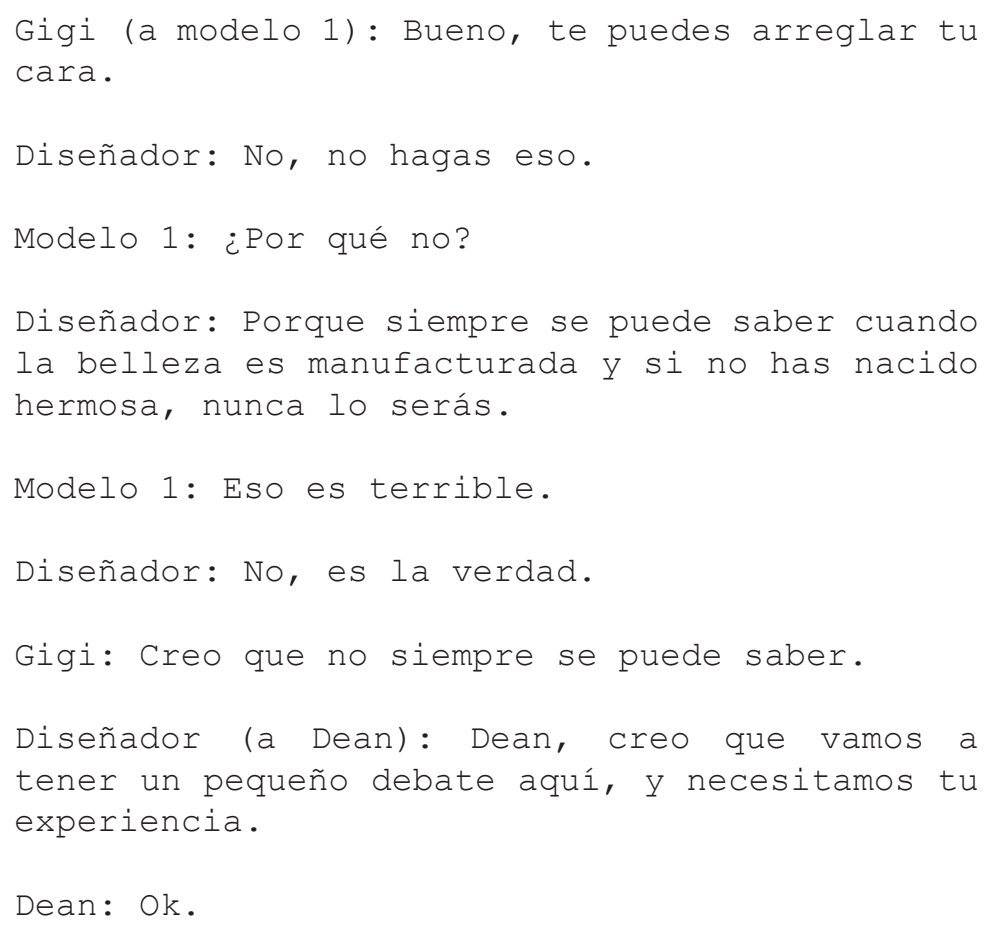




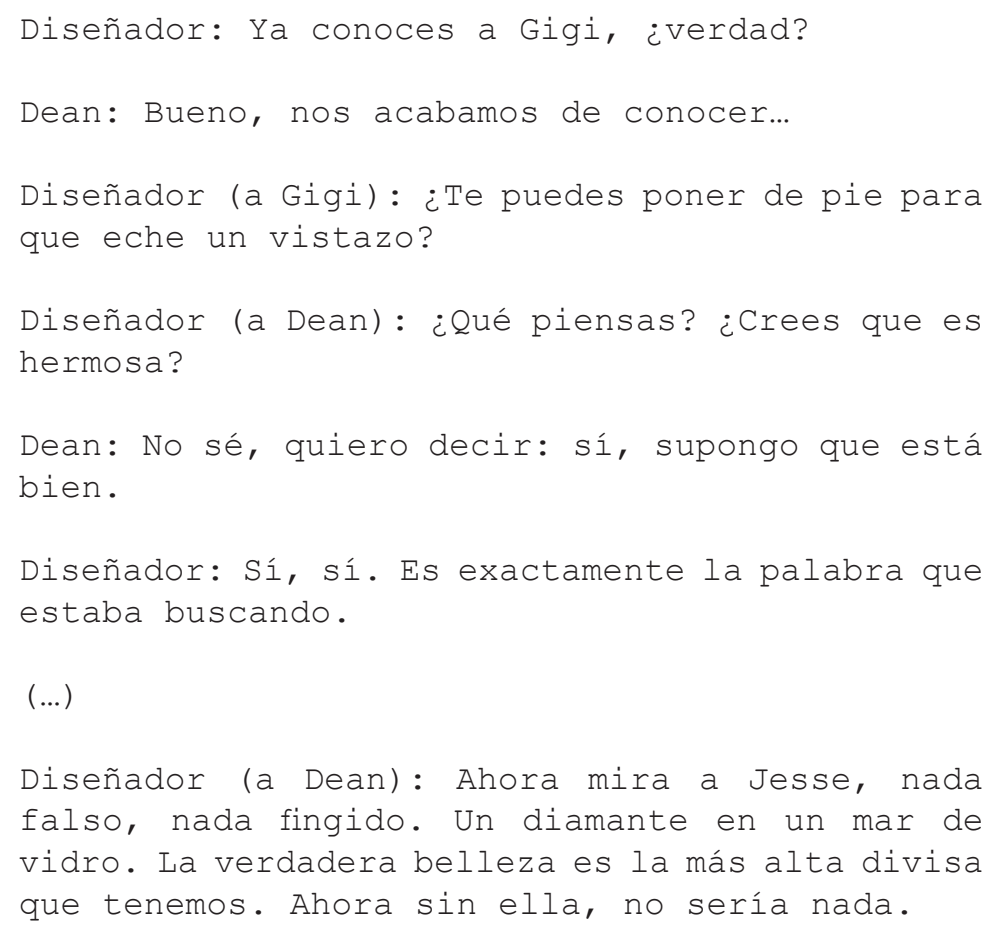

En el diálogo pasado radica una forma ensayística potente: la idea platónica sobre la belleza, en la que esta es percibida por los sentidos, especialmente por la vista, es emplazada para destruir una postura naif donde la belleza procede de un "interior" y por ser profunda y no superficial es buena. Esta forma de pensar la belleza del ser humano es objetada una y otra vez por las diversas secuencias que apuntalan la tesis del audiovisual que aquí trato.

De esta manera estos diálogos guardan una estrecha relación con la tesis de la película, específicamente esta última aseveración: la belleza es la única cosa (que importa). Aquí está contenida una declaración sobre lo terrible que es no poseer belleza en este tipo de sociedad, y más aún que la belleza es puesta también en la misma categoría ontológica que la verdad, así la verdad está subsumida en la belleza y la belleza ex natura es el valor aunado a ser algo capaz de ser poseído.

Esta forma de pensar sobre el cuerpo y lo bello, constantemente aludida a lo largo de la película, puede encontrarse muchas veces de manera alegórica; como ejemplo más visible, la secuencia donde Jesse es invitada por Ruby a una fiesta.

En la fiesta, como acto central, se lleva a cabo un performance en el que empleando luces estroboscópicas como iluminación un cuerpo asexuado por la indumentaria, vendado de tal manera que las facciones del rostro no se distinguen. El cuerpo es ascendido a través de lo que parece ser una técnica shibari, sometido y elevado ante los ojos expectantes y alegres de Jesse y Ruby como forma triangular de un flirteo y emoción. Dicha emoción o alegría ante lo novedoso por parte de Jesse es yuxtapuesta en una serie de planos en los que se muestran rasgos de aburrimiento y monotonía de las dos modelos, Gigi y Sarah [Figura 4].

\section{CONCLUSIÓN}

En esta propuesta de lectura hemos relacionado elementos que informan la diégesis en la configuración de un personaje teniendo por base hipotextos bíblicos que aluden al mito de la caída de Lucifer, así como su transformación y apropiación a través de alegorías construidas desde lo cromático hasta la sustitución de elementos llevadas a cabo en la narrativa audiovisual.

Esta reapropiación y construcción de los hipotextos están en función de una serie de declaraciones que permiten reconstruir una puesta en crisis de los valores estéticos de la sociedad occidental y occidentalizada. En esta propuesta estética la condición de falso juega un papel de suma importancia, según lo he sostenido. De esta forma, según el canon de la cinta, la suma belleza natural es algo que trastoca e irrumpe en las relaciones interpersonales provocando una suerte de hybris, de maldición, para quien la posee o la ostenta, la verdad como algo terrible (deina) que solo puede entenderse desde 
la estética. Una propuesta estética que este caso interpela y redarguye a la estética epicúrea con un ejemplo ostensible: la trasformación (decadencia) de Jesse. Recordemos que, para la estética epicúrea, que es una de las que más influjo tienen en la moral cristiana, lo bello es isomórfico y equivalente a lo bueno. La fealdad por el contrario sería un atributo contrario a lo divino, ya que sería también falso, y propio de lo demoniaco (como opositor al bien mayor o sumo bien). En este aspecto la estética aristotélica daba cuenta ya de esta esta discusión a su modo: problematizando argumentativamente la relación natural entre lo verosímil y lo bello. Esta relación es tratada de diferentes formas y gradientes en el filme para probar cómo ni la belleza que procede de lo natural, encarnada en Jesse, o en la que interviene artificio, como la que exponen Gigi o Sarah, está vinculada de modo alguno con la bondad o con los atributos de honestidad y dignidad (honestum y decorum en el sentido estético epicúreo, como en Crisipo y Séneca). Sino que la belleza que entendida como valor de cambio, plusvalía, impronta de ascenso social y bienestar económico, como equivalente - para una sociedad enclavada en el reino del sensorium - de poder, trae consigo los vicios de este y finalmente termina por corromper y corromperse. Así, puede entenderse que, en las relaciones con la verdad, exhibidas en El demonio neón se encuentran descoyuntadas de lo ético, para descansar, a la postre, en el campo de la estética. 


\section{Bibliografía}

\section{Filmografía}

Refn, N. W. (Director y Productor) \& Børglum, L. (Productora). (2016). El demonio neón [The Neon Demon]. Dinamarca, Francia, Estados Unidos: Wild Bunch,

Gaumon, Space Rocket Nation.

Miguel Sánchez Soto (México) es Licenciado en Letras Hispánicas y Maestro en Comunicación por la Universidad de Guadalajara. Actualmente cursa el Doctorado en Educación en la misma casa de estudios.

Elizondo, S. (1992). Teoría del infierno y otros ensayos. Ciudad de México, México: El Colegio Nacional.

Genette, G. (1989). Palimpsestos. La literatura de segundo orden. Madrid, España: Taurus. GIRARD, R. (1986). El chivo expiatorio. Barcelona, España: Anagrama.

GIRARD, R. (1999). Veo a satán caer como el relámpago. Barcelona, España: Anagrama.

Lorenz, E. (1993). The Essence of Chaos. Seattle, EE.UU.: University of Washington Press.

Worton, M. y Still, J. (1991). Intertextuality: Theories and Practices. Nueva York, EE.UU.: Manchester University Press.

Yehy, N. (2001). El cuerpo transformado. Cyborgs y nuestra descendencia tecnológica en la realidady en la ciencia ficción. Ciudad de México, México: Paidós. 